\title{
How do consumers express their appreciation of wood surfaces? Norway spruce floors in Germany as an example
}

\author{
Andreas Manuel $^{1} \cdot$ Rainer Leonhart $^{2} \cdot$ Olof Broman $^{3} \cdot$ Gero Becker $^{1}$
}

Received: 20 September 2015 / Accepted: 12 May 2016/Published online: 7 June 2016

(C) INRA and Springer-Verlag France 2016

\begin{abstract}
- Key Message A variety of visually different floor samples are presented online to consumers. Based on their individual verbal judgements of appreciation for visual surface characteristics, four distinct groups of floor surfaces were identified. This allows directing design and marketing efforts more precisely towards consumers' expectations.

- Context For high-end wood products, appearance is a key factor. Traditionally, manufacturers grade wood considering technical parameters and industrial customers' requirements. In contrast, knowing the consumers' verbal items would be of advantage for both producers and buyers.
\end{abstract}

Handling Editor: Jean-Michel Leban

Contribution of the co-authors Andreas Manuel: writing the paper, data acquisition and designing the online questionnaire, running the data analysis and processing digital image data

Rainer Leonhart: supervising the research design (survey studies) and supervising the statistical data analysis

Olof Broman: supervising the online surveys and image processing, revising the manuscript and designing the experiment

Gero Becker: overall concept of the project, supervising the work and revising the manuscript

Andreas Manuel

andreas.manuel@fob.uni-freiburg.de

1 Chair of Forest Utilization, University of Freiburg, Breisgau, Germany

2 Department of Social Psychology and Methodology, University of Freiburg, Breisgau, Germany

3 Division of Wood Science and Engineering, Luleå University of Technology, Luleå, Sweden
- Aims Three research questions are identified exploring possibilities to utilize consumers' appreciations. (1) Is it possible to establish a consistent characterization with verbal items? (2) Can appreciation be linked to visual wood properties? (3) Can the great natural variety of wood surfaces be assigned to desirable product groups?

- Methods Out of 57 spruce logs, 810 floor boards were produced and sorted into 15 'visual classes' (VC). Images were retrieved and virtual floors composed from each VC. Consumers evaluated selected floor samples in an online survey using a set of 7 items. Hierarchical cluster analysis and discriminant analysis are applied to analyze the answers.

- Results Only 4 out of the 7 items ('vividness', 'evenness', 'contrast' and 'stripes') were sufficient to allocate the VCs to four groups which represent different consumer appreciations. Inverse assessments of different product groups support a more differentiated marketing.

- Conclusion The results indicate that verbal judgements of high-end wood surfaces can hold advantages directing production and marketing efforts more towards consumers' preferences and thus increasing satisfaction and added value.

Keywords Consumer preferences · Wood surface · Floor production $\cdot$ Timber quality $\cdot$ Picea abies

\section{Introduction}

Wood as an element of aesthetic design in private homes, business settings and for many other high-end applications is appreciated as a premium material. Rooms which show wood design elements are favoured by many end-consumers (Rice et al. 2006).

Wood products with an aesthetically excellent final design are the result of a cascade of various processing steps from the 
$\log$ to the finished product, where much effort is put to achieve a high customer oriented quality level like, e.g. in the veneer industries (cf. Wiedenbeck et al. 2004). In the wood processing industry, wood quality is traditionally graded based on technically measureable wood features (often regarded as defects) e.g. knots, fibre orientation and colour deviation. Professional customers determine their needs according to these parameters and with regard to their intended requirements for the product, as grain patterns, colour and various types of surface finishes can enhance the aesthetical performance of wood surfaces (Wiemann 2010).

In contrast, considering the non-expert consumer's perception is not common in wood processing industries. An information gap is often observed between producers and consumers regarding the consumers' aesthetical requirements and preferences (Pakarinen 1999; Weinfurter and Hansen 1999). A deeper knowledge about consumers' preferences is considered as increasingly relevant and recommended to strengthen market competitiveness (Nyrud 2012).

Based on a survey about pine floors in Sweden, Broman (2001) concludes that consumers can describe a wood surface by items like 'strict', 'restful', 'rich', 'contrast', 'lively' and 'eventful' and their preferences are affected by the balance between degrees of 'harmony' and 'activity' in knotty wood surfaces. The same author stated that consumers tend to find it easier to describe what they do not like in wood surfaces instead of what they positively prefer (Broman 2003). A diverging judgement comparing consumers and professionals was also revealed in the case of red alder furniture by Bumgardner et al. (2009). Among consumers was found that character marks, design and naturalness are positively related to willingness-to-pay (Bumgardner et al. 2009). Among retailers, an opposite effect was observed indicating their preferences are negatively correlated with increasing character-mark size (Bumgardner et al. 2001). A preference study based on a pairwise comparison of visually different floor samples, using the same material as this study, revealed that visual extremes can be more attractive to consumers than unexceptional surfaces (Manuel et al. 2015). However, it is still unclear what subjective items are appropriate to test the consumers' appreciation using verbal expressions and thereby enable depicting different aesthetical surface characteristics.

The visual appearance of the wood surface as one relevant criterion for consumers to select their preferred wood product is the focus of this study and assumed to be decisive for market competitiveness. The characterization of relevant visual, subjective surface parameters is a first step in identifying the complexity of what consumers appreciate and hereby improve market communication taking the end-consumers' language into account. Shaping product design, processing steps and marketing activities according to the findings may improve added value and consumer satisfaction.
Taking the example of solid wood floors from Norway spruce logs, cut and processed in Germany in the southern Black Forest, this study aims in this context:

(1) to identify subjective items, considered in earlier studies to be significant that characterize differences in the consumers' appreciation for visually distinct wood surfaces,

(2) to explore if these items can be linked to visual surface parameters which are relevant for the production of wood surfaces and therefore useful to support consumer oriented product design and marketing and

(3) to assign the great natural variety of wood surfaces to a limited number of desirable product groups based on the consumers' individual appreciation, and by this reduce complexity in production and marketing and create added value for the whole range of natural wood quality.

\section{Material}

Floors made from boards of Norway spruce (Picea abies [L.] Karst.) were chosen as an example in this study. Out of 57 spruce logs with $4 \mathrm{~m}$ length, a total of 810 floor boards with $4000 \times 110 \times 20 \mathrm{~mm}(101 \mathrm{~mm}$ decking width $)$ were produced as kiln dried, planed and tongue and groove matchboards with an oil surface finish (transparent water based wood floor finish with UV protection). Out of these 810 boards, 425 (52\%) were technically accepted to produce floor boards showing a minimum length of $2 \mathrm{~m}$ without knotholes, loose knots, splits or other technically unacceptable defects. Two wood experts with scientific background inspected and sorted the boards manually based on the visual appearance of the surface characteristics. The technically accepted floor boards were sorted aiming homogeneous groups of visually similar floor boards which led to 15 distinctively different visual classes (VC). The same material and VCs were tested in Breinig et al. (2015) to establish a technical board classification based on measured variables, mainly quantitative descriptors of different knot attributes (e.g. size, state) and distribution (e.g. count, distance to nearest neighbour). Sorting attributes were visually relevant surface parameters like grain orientation (standing or laying grain), knot aspects, background structure/colour (e.g. compression wood) or pith. Descriptive characteristics of each VC are presented in Table 1 of Manuel et al. (2015). The VCs 1 to 5 represent different facets of boards with standing grain. The VCs 6 to 15 represent facets of flat grain including both boards from the log centre zone (e.g. VC 12) and boards showing visible pith (VC 10). In Fig. 1, 15 floor samples illustrate these VCs that were produced $(2 \mathrm{~m} \times 1 \mathrm{~m})$ and each was composed of ten boards from the same VC.

Digital image data of the 425 floor boards were acquired with an industrial board scanner (single board scanning 
Table 1 Cross-table presenting the image sample frequency distributions within the four cluster solution achieved from hierarchical cluster analysis and stepwise discriminant analysis (DA)

\begin{tabular}{llllll}
\hline VC & C11 & Cl2 & Cl3 & Cl4 & Total \\
\hline 1 & $7 / 10$ & $4 / 1$ & $0 / 0$ & $0 / 0$ & 11 \\
2 & $10 / 10$ & $1 / 1$ & $0 / 0$ & $0 / 0$ & 11 \\
3 & $4 / 3$ & $6 / 6$ & $1 / 0$ & $0 / 2$ & 11 \\
4 & $0 / 0$ & $1 / 1$ & $5 / 5$ & $5 / 5$ & 11 \\
5 & $1 / 0$ & $8 / 9$ & $2 / 2$ & $0 / 0$ & 11 \\
6 & $3 / 1$ & $8 / 8$ & $0 / 1$ & $0 / 1$ & 11 \\
7 & $0 / 0$ & $0 / 0$ & $9 / 10$ & $2 / 1$ & 11 \\
8 & $0 / 0$ & $0 / 0$ & $6 / 9$ & $5 / 2$ & 11 \\
9 & $0 / 0$ & $3 / 1$ & $7 / 9$ & $1 / 1$ & 11 \\
10 & $0 / 0$ & $0 / 0$ & $4 / 4$ & $7 / 7$ & 11 \\
11 & $0 / 0$ & $4 / 4$ & $6 / 6$ & $1 / 1$ & 11 \\
12 & $1 / 0$ & $2 / 1$ & $6 / 7$ & $2 / 3$ & 11 \\
13 & $0 / 0$ & $0 / 0$ & $8 / 9$ & $3 / 2$ & 11 \\
14 & $0 / 0$ & $0 / 0$ & $9 / 10$ & $2 / 1$ & 11 \\
15 & $0 / 0$ & $0 / 0$ & $5 / 9$ & $6 / 2$ & 11 \\
Total & $26 / 24$ & $37 / 32$ & $68 / 81$ & $34 / 28$ & 165 \\
\hline
\end{tabular}

The first figure represents the results from hierarchical cluster analysis. The second figure represents the resulting cluster $(\mathrm{Cl})$ assignment predicted through stepwise DA

line camera system). Adjustment of the images' aspect ratio (interpolation) was necessary compensating the lengthwise image compression of 0.21 approximately caused by the feed speed in relation to the line rate. Digital image processing was accomplished in ImageJ (Rasband 2014). The raw image data of the RGB channels lead to a rather unnatural, dark and greyish representation of the board surfaces on the screen. According to recommendations by Broman (1995) and Nordvik and Broman (2009), to slightly exaggerate a reddish tint in order to obtain a warmer look, the colour was manually adjusted. A good result was achieved with enhanced brightness $(+60)$ and colour $(\mathrm{R}+71, \mathrm{G}+6, \mathrm{~B}-36)$. The adjustment was done with default settings on the screen and tested with different screens. While the choice of screens and screen settings in an online survey cannot be controlled, the final look of the images remains always a compromise.

Virtual floor sample images were then generated, each from ten board images from one $\mathrm{VC}$ using a random selection procedure where each board image was only allowed to be present once in one floor sample image, so 'doublets' or more repetitions of one specific board image did not occur in the same floor sample. Following this procedure, 11 floor samples were composed from each VC resulting in $11 \times 15=165$ floor sample images. The floor images were 600 pixels long and 300 pixels wide representing the board surface dimensions of $2 \mathrm{~m}$ and $1 \mathrm{~m}$, respectively. On a standard 19" computer monitor, the presentation of one floor image $(600 \times 300$ pixels $)$ was $190 \mathrm{~mm}$ (height) and $95 \mathrm{~mm}$ (width).

The described procedure resulted in a maximum visual homogeneity of the floor sample surface taking into account the findings that mismatching disharmonious visual features might cause rejection by consumers (Broman 1995).

\section{Methods}

To reach a sufficiently high number of consumers with limited resources, floor sample images were presented in an online survey addressing individuals who already took part in a previous study (Manuel et al. 2015). The questionnaire was designed in UNIPARK (EFS Survey, (C) 2014 QuestBack AG). The survey was distributed in German language. It was assumed that the respondents would be reluctant to evaluate all 165 image samples from all $15 \mathrm{VCs}$ demanding far too much of their time. To reduce complexity and completion time, and thereby minimize effects of 'satisficing' with regard to response rate, data completeness and data quality (cp. Krosnick 1991), out of the pool of 165 sample images, only five were randomly selected and presented to each respondent.

These five presented images were selected according to the following procedure: The VCs were sorted into five pre-groups by a wood expert with regard to their relative visual similarity taking into account the most important visual wood surface features (1) background structure (grain direction) and (2) knots (size and colour). Inevitably by this pre-grouping procedure, finer details of the visual surface structure are merged. On the other hand, it is ensured that images containing the most prominent visual features are presented to each respondent. Thus, pre-group 1 included the VCs 1, 2 and 5; pre-group 2 VCs 3, 4 and 7; pre-group 3 the VCs 6, 9 and 11; pre-group 4 the VCs 10, 12 and 14; and pre-group 5 the VCs 8, 13 and 15 (Fig. 1). For each respondent, one floor image out of each pregroup was randomly selected and presented, and so the wide variety of all 165 image samples was still reflected.

To individually evaluate and characterize the visual appearance of each of the five different floor images presented, seven evaluation items were offered to the respondents. The seven items offered in German language, were 'Gleichmäßigkeit' (evenness), 'Kontrastreichtum' (contrast), 'Harmonie' (harmony), 'Lebendigkeit' (vividness), 'Anzahl der Äste' (number of knots), 'Flecken' (dots) and 'Streifen' (stripes). Most of these items were taken from former studies which identified them to be relevant in this context, e.g. 'contrast' in Nordvik and Broman (2009) and Broman (2001), 'harmony' in Sande and Nyrud (2008) and Broman (2001), 'vividness' in Nordvik et al. (2009) and (syn. lively) Broman (2001), 'evenness' in Nyrud et al. (2008), Høibø and Nyrud (2010) and Broman (2003), 'number of knots' in Wang et al. (2004) and Høibø and Nyrud (2010), 'dots' in Broman (1995). The item 'stripes' 
Fig. 1 Wood floor images $(2 \times 1)$ representing the $15 \mathrm{VCs}$ (black figures), composed out of ten boards from the respective VC. Different frames indicate the assignment of the floor samples to the four clusters (Table 1).

Figures in brackets represent the pre-groups 1 to 5 used for random selection in the questionnaire

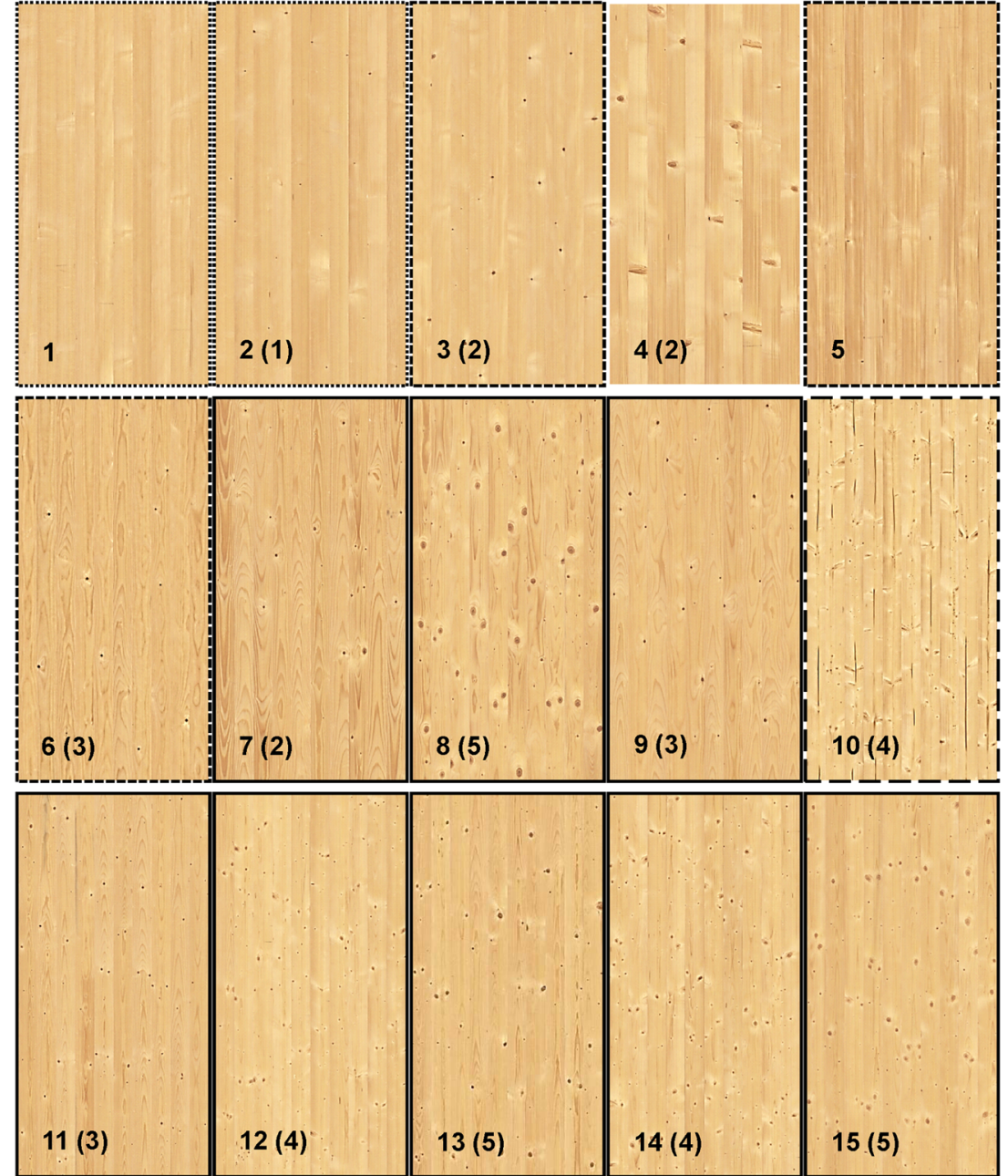

was added to address pith as a unique feature of the spruce floor boards presented.

The respondents could rate each item according to a sevenpoint Likert scale from $1=$ 'low attractiveness' to $7=$ 'high attractiveness'. A pre-test among German test persons indicated that using these seven items to evaluate each of the five images could be achieved within a time frame of 5-10 min, which was assumed, would result in a high number of completed responses.

To identify distinct groups of similarly assessed image samples from the 165 floor images, the responses were statistically analyzed using an explorative approach with a combination of (1) hierarchical cluster analysis and (2) discriminant analysis. Hierarchical cluster analysis using the Ward's method and squared Euclidian distance is a stepwise agglomerative procedure (Hair et al. 2010). In this study, hierarchical cluster analysis is applied to determine a number of meaningful clusters (groups) of visually similar floor images. It was assumed that out of the 15 visually different VCs similar images can be grouped into distinct clusters through hierarchical cluster analysis according to the consumers' assessment. Those clusters of similar images were then compared with the experts' assignment to the $15 \mathrm{VCs}$.

Stepwise discriminant analysis is applied to estimate a discrimination model predicting the clusters achieved by hierarchical cluster analysis and to identify out of the seven items offered in the questionnaire those items which provide a significant contribution to the discrimination effects (portion of explained variance). Wilk's lambda was chosen as the selection criterion $\left(F_{\text {in }}=2.71\right.$ and $F_{\text {out }}=3.84$ used by default). All statistical analyses were calculated in IBM SPSS Statistics 22 (IBM Corp. 2013).

Furthermore, in the questionnaire, some basic sociodemographic data (age, gender, professional background, expertise related to wood) was requested from each respondent to enable a more detailed characterization of the respondents.

\section{Results}

The online questionnaire was active for 119 days and the survey's website was accessed 714 times (100\%). Out of 
these, 571 respondents $(80.0 \%)$ started to answer and 461 $(64.6 \%)$ completed the questionnaire. Cancelled access before completion was found in 110 cases $(15.4 \%)$ which was determined when $>10 \%$ of the variables $(7$ items $\times 5$ floor samples), remained unrated. Rating results were examined by explorative data analysis. Respondents who show for more than $10 \%$ of the tested variables 'extreme ratings' (responses 'outside' and 'far outside' according to Tukey 1977) were excluded from further analysis $(n=39,5.46 \%)$. The remaining sample pool of $422(59.10 \%)$ validated respondents was further analyzed.

Among 422 validated respondents, 50 respondents $(11.9 \%)$ did not report their socio-demographic data. Among the given respondents, 244 (57.8\%) reported to be male and 177 (41.9\%) to be female. The total sample revealed an average age of 39 years (mean 38.7, $\min =17, \max =78$, $\mathrm{SD}=13.75,1$ missing). For the variable 'age', Shapiro-Wilk's test revealed significant deviation from normal distribution $(p<0.001)$. A bimodal frequency distribution can be observed with a local frequency minimum near the average age. The respondents reported their occupational status as follows: employee $46.7 \%$, university student $23.0 \%$, public servant $16.4 \%$, self-employed/freelance $6.4 \%$ and other $7.5 \%$. An occupation related to wood was reported by 239 respondents (56.6\%), and 105 persons (24.9\%) qualified themselves as wood experts. Four hundred eight $(96.7 \%)$ reported German as their mother tongue, $13(3.1 \%)$ another language and one no response.

When it comes to practical production and marketing of wooden floors, it would be desirable to reduce complexity by grouping the $15 \mathrm{VCs}$ into a significantly smaller number of different groups of floor types. Among the 165 tested images, hierarchical cluster analysis was computed to find a reduced but meaningful number of clusters (groups) based on the respondents' feedback $(n=422)$. The dendrogram (Fig. 2$)$, resulting from the clustering procedure, illustrates the agglomeration and helps to identify clusters $(\mathrm{Cl})$ of the floor samples which were rated similarly (based on average ratings of the 165 samples compared). The horizontal distances indicate the similarity within and the standardized differences between the clusters. This dendrogram suggests that a three- or a fourcluster solution would be meaningful because of their relatively close horizontal distance.

The preferred final cluster solution should result in a clear assignment of the samples which allows identifying those VCs which can be clearly grouped into one cluster. As a threshold for a clear assignment, we chose the ratio between the distribution of the samples of one VC between two or more clusters being at least $0.67(4 / 6)$ or lower (e.g. $3 / 7=0.43$ ). Accordingly, the sample distribution indicates the best results for the four-cluster solution which retrieves clear assignments for VCs 1 and 2 in $\mathrm{Cl1}$; the VCs 3, 5 and 6 in $\mathrm{Cl} 2$; the $\mathrm{VCs} 7,9,11,12,13$ and 14 in $\mathrm{Cl} 3$; and $\mathrm{VC} 10$ in

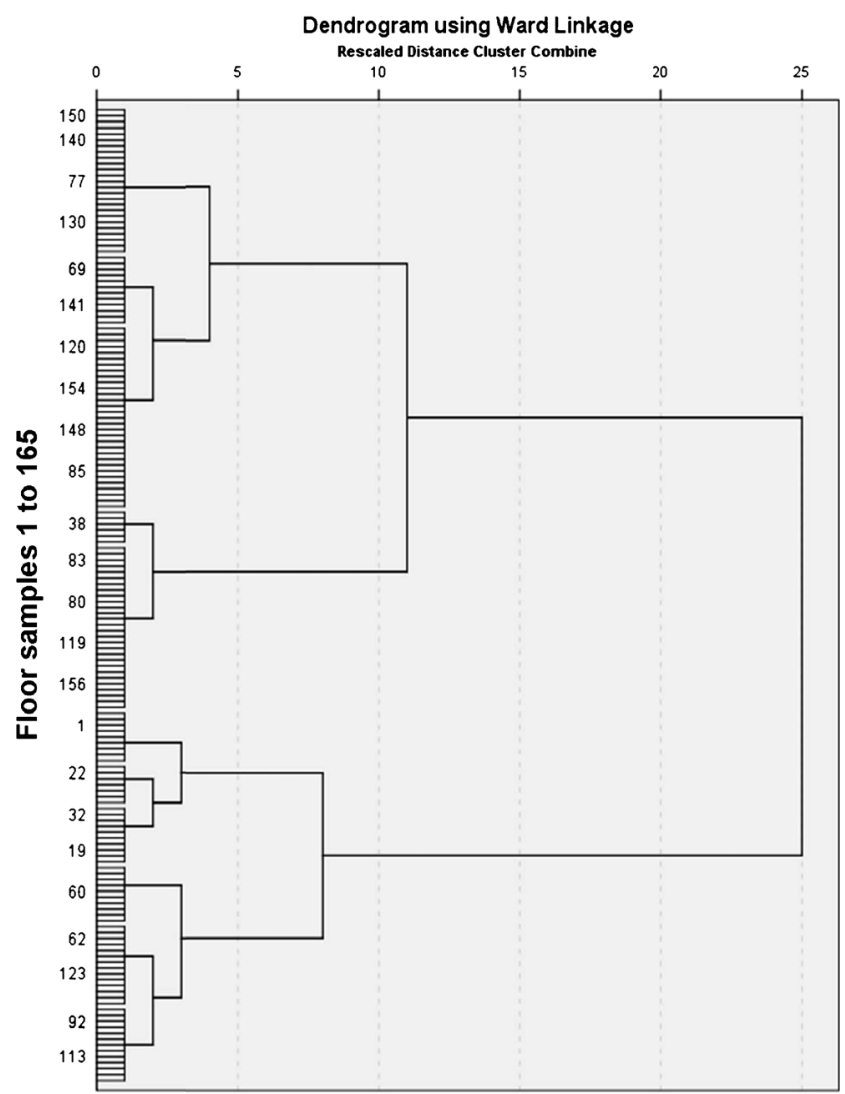

Fig. 2 Dendrogram from hierarchical cluster analysis used with Ward Linkage and squared Euclidian distance. The horizontal axis indicates the distance between the clusters that helps identifying a meaningful number of clusters with a high degree of differentiation (long distances)

Cl4 (Table 1). No clear assignment is found for the VCs 4,8 and 15. Thus, the four-cluster solution reveals a high degree of differentiation among the $15 \mathrm{VCs}$ but the results represent acceptable cluster assignments nevertheless.

This cluster assignment of all 165 images into four clusters is examined with discriminant analysis. Discrimination effects are tested with regard to a maximum cluster differentiation. Therefore, classification models are estimated, critical variables selected and the discrimination power of the fourcluster solution tested using stepwise discriminant analysis.

In order to test the clustering result, only those samples from one $\mathrm{VC}$ were included for model estimation which were assigned clearly to a majority cluster $(n=91)$, but misclassified samples were excluded. Stepwise selection revealed the four items 'vividness', 'evenness', 'contrast' and 'stripes' as significant (Table 2). Furthermore, three significant discrimination functions (F1, F2 and F3) separate the clusters with Eigen values of $7.05,0.720$ and 0.073 , respectively (Table 4). Based on this model, an overall correct classification of $94.5 \%$ is obtained. In detail, the probability of correct clustering is illustrated in Table 3.

The standardized canonical discriminant function coefficients help to identify the proportional weight (importance) 
Table 2 Four items with significant contribution tested stepwise and entered in the analysis based on Wilk's lambda

\begin{tabular}{llllllllll}
\hline Step & Entered items & Wilk's lambda & $\mathrm{df}_{1}$ & $\mathrm{df}_{2}$ & $\mathrm{df}_{3}$ & $F$-statistic & $\mathrm{df}_{1}$ & $\mathrm{df}_{2}$ & Sig. \\
\hline 1 & Vividness & 0.15 & 1 & 3 & 87 & 160.45 & 3 & 87 & $<0.001$ \\
2 & Evenness & 0.09 & 2 & 3 & 87 & 65.54 & 6 & 172 & $<0.001$ \\
3 & Contrast & 0.08 & 3 & 3 & 87 & 42.93 & 9 & 207.02 & $<0.001$ \\
4 & Stripes & 0.07 & 4 & 3 & 87 & 32.90 & 12 & 222.54 & $<0.001$ \\
\hline
\end{tabular}

At each step, the variable that minimizes the overall Wilk's lambda (portion of unexplained variance to total variance) was entered. High $F$ values indicate high variability and better separation between the clusters of each item within the discriminant functions (Table 4). Results indicate that the item 'vividness' $(0.65)$ is most effective in F1, 'evenness' (0.62) in F2 and 'contrast' $(0.56)$ and 'stripes' (-1.11) in F3.

The resulting descriptive cluster characteristics are presented with the average ratings of the tested items in Table 5. In comparison with the overall average item rating of 4.11 , divergent cluster characteristics (high or low ratings) are highlighted. Regarding each item separately, in Cl1, high ratings ( $>4.11)$ are given regarding 'evenness' and 'harmony'. In $\mathrm{Cl} 2$, high ratings $(>4.11)$ are given for 'evenness', 'harmony' and 'stripes'. In $\mathrm{Cl} 3$, high ratings ( $>4.11)$ are given for 'contrast', 'harmony', vividness, 'number of knots' and 'stripes'. In $\mathrm{Cl} 4$, high rating (>4.11) is given for 'vividness'. The detailed cluster ratings are visualized in Fig. 3.

Out of these results, it is obvious that a parallel rating pattern can be observed between $\mathrm{Cl} 1$ and $\mathrm{Cl} 2$ as well as between $\mathrm{Cl} 3$ and Cl4. An oppositional rating effect is observed between the cluster pairs $\mathrm{Cl} 1$ and 2 and $\mathrm{Cl} 3$ and 4 . This effect is especially expressed for the items 'evenness', 'harmony', 'contrast' and 'vividness'.

The floor sample images presented in Fig. 1 were previously used to illustrate consumer preference groups as a result of a preference study (Manuel et al. 2015). In the present study, the floor sample images are highlighted with different frames according to the respective cluster assignment as a result of a clustering of floor sample images. The floor images in Cl1 feature standing grain, clear surfaces and surfaces containing very few, small black knots. $\mathrm{Cl} 2$ shows standing grain and flat grain and features small black knots as the common visual characteristics. $\mathrm{Cl} 3$ on the other hand features surfaces in flat grain, with small, medium to large knots. Cl4 features pith (VC10) especially. Only VC4 could not be clearly assigned to any cluster in this study. A Kruskal-Wallis test was applied (alpha level 0.5) on the deviating rating results for $\mathrm{VC} 4$ in $\mathrm{Cl} 3$ and $\mathrm{Cl}$. It revealed significant rating differences for all three items 'evenness', 'contrast' and 'vividness'.

\section{Discussion}

The results from the online questionnaire show that endconsumers are able to express their appreciation of spruce wood floor surfaces with their normal (non-technical) language, using a set of seven verbal expressions (items). Earlier findings point to similar items which have been already useful for instance with pine floors and Swedish consumers (Broman 2001). In this study, only four of the given items (vividness, evenness, contrast and stripes) were statistically significant to discriminate clearly distinct wood surfaces based on the stated consumers' appreciation. Other items may be of critical relevance to characterize lesser pronounced features. This result enables manufacturers to focus product design and marketing of high value wood products more directly towards end-users preferences.
Table 3 Cluster prediction results according to the estimated discriminant model testing the four clusters solution found via hierarchical cluster analysis

\begin{tabular}{lllllll}
\hline & & Cluster 1 & Cluster 2 & Cluster 3 & Cluster 4 & Total \\
\hline Count of images & Cluster 1 & 16 & 1 & - & - & 17 \\
& Cluster 2 & - & 21 & 1 & - & 22 \\
& Cluster 3 & - & 2 & 43 & - & 45 \\
& Cluster 4 & - & - & 1 & 6 & 7 \\
& Ungrouped & 8 & 8 & 36 & 22 & 74 \\
Proportions (\%) & Cluster 1 & 94.1 & 5.9 & - & - & \\
& Cluster 2 & - & 95.5 & 4.5 & - & \\
& Cluster 3 & - & 4.4 & 95.6 & - & \\
& Cluster 4 & - & - & 14.3 & 85.7 & \\
& Ungrouped & 10.8 & 10.8 & 48.6 & 29.7 & \\
\hline
\end{tabular}

Of the original clustered cases $94.5 \%$ were correctly classified 
Table 4 Standardized coefficients $(b)$ and Eigen values of the discriminant functions F1, F2 and F3. The coefficients describe the relative relevance of each item (variable weight) within the function

\begin{tabular}{|c|c|c|c|c|}
\hline Entered items & & $b_{\mathrm{F} 1}$ & $b_{\mathrm{F} 2}$ & $b_{\mathrm{F} 3}$ \\
\hline & Eigen value & 7.05 & 0.72 & 0.073 \\
\hline 'evenness' $\left(b_{1}\right)$ & & -0.40 & 0.62 & -0.14 \\
\hline 'contrast' $\left(b_{2}\right)$ & & 0.37 & 0.31 & -1.11 \\
\hline 'vividness' $\left(b_{3}\right)$ & & 0.65 & -0.10 & 0.80 \\
\hline 'stripes' $\left(b_{4}\right)$ & & 0.05 & 0.54 & 0.56 \\
\hline
\end{tabular}

The discriminant scores $D$ from the functions $F$ are calculated for each case which determine the position in the three dimensional discriminant space and help to determine the respective cluster assignment according to the discriminant model

$D_{\mathrm{F}}=b_{1}$; evenness $+b_{2}$; contrast $+b_{3}$; vividness $+b_{4}$; stripes

The clustering results show that classifying surface characteristics of floor surfaces with a high resolution into $15 \mathrm{VCs}$, determined by experts with a scientific background in wood technology, turned out to be unnecessarily detailed compared to the consumers' perceptions. Already with a four-cluster solution, a meaningful and valid discrimination into distinct groups of differently appreciated wood surfaces can be achieved. This reduces the complexity for future consumer oriented product design and marketing efforts because, from the consumers' perspective, floors with visually and also technically different surface characteristics (e.g., VC1 and VC2 or $\mathrm{VC} 8$ and $\mathrm{VC} 15)$ can be grouped into one specific product group, respectively.

In $\mathrm{Cl} 1$ and $\mathrm{Cl} 2$, surface samples are rated high for the items 'evenness' and 'harmony' and rated low for the items 'contrast' and 'vividness'. In $\mathrm{Cl} 3$ and $\mathrm{Cl} 4$, this rating pattern is found to be inverse. The effect of distinct and even inverse characterization of appreciated and visually different wood surfaces opens a consumer specific perspective that may promise a more efficient use of the raw material and an increased overall added value if the products' qualities differ from conventional sorting grades. For instance, floor boards representing big sound knots are not downgraded or rejected (as it may be the case today in the wood processing industries), but can be selected and composed to produce floors with a specific optical surface, which attracts consumers who highly appreciate this look described predominantly by the items 'contrast' and 'vividness'. This is supported by the fact that $\mathrm{Cl} 3$ got the highest overall average rating of 4.33 and the highest absolute rating on 'vividness' of 5.00 (Table 5). The findings indicate that consumers express their appreciation of different visual wood surface features differently which open a new perspective towards a more consumer focused marketing.

In this study, the ratings between $\mathrm{Cl} 1$ and $\mathrm{Cl} 3$ show the clearest differences and are also opposite. A more expressed heterogeneity among the respondents might have resulted in less pronounced clustering results. The study of Manuel et al. (2015) examined differences between consumers' preferences which turned out to be rather heterogenic.

Furthermore, 'parallel rating' is observed between $\mathrm{Cl1}$ and 2 and between $\mathrm{Cl} 3$ and 4, respectively, which also means that these two pairs of clusters represent similar item expressions but on different levels of appreciation (higher or lower). The fact that the $\mathrm{Cl} 2$ and $\mathrm{Cl} 4$ indicate lower ratings than $\mathrm{Cl} 1$ and $\mathrm{Cl} 3$ may suggest products of intermediate quality according to the respondents' judgments. The higher ratings for $\mathrm{Cl} 1$ and $\mathrm{Cl} 3$ on the other hand would then both indicate from the consumers' perspective premium product surfaces, even if $\mathrm{Cl} 3$ contains large (but sound) knots.

$\mathrm{VC} 4$ could not be clearly assigned to one cluster based on the consumers' rating but is equally dispersed between $\mathrm{Cl} 3$ and $\mathrm{Cl} 4$. The highest rating is found on 'vividness' $(5.0 \mathrm{in} \mathrm{Cl} 3$ and 4.34 in Cl4), the lowest on 'evenness' (4.04 in $\mathrm{Cl} 3$ and 3.43 in C14), and significant differences are found in 'vividness', 'evenness' and contrast'. This, on the one hand,

Table 5 Average item ratings of the four cluster solution predicted via discriminant analysis. Items entered in the analysis are italicized as well as their maximum cluster ratings (overall average rating 4.11)

\begin{tabular}{|c|c|c|c|c|c|c|c|c|c|c|}
\hline Cluster & & Evenness & Contrast & Harmony & Vividness & Number of knots & Dots & Stripes & Cluster mean and SD & Valid $n$ \\
\hline \multirow[t]{2}{*}{$\mathrm{Cl1}$} & Mean & 4.91 & 3.01 & 4.48 & 2.91 & 3.42 & 3.61 & 3.97 & 3.75 & 25 \\
\hline & $\mathrm{SD}$ & 0.51 & 0.33 & 0.60 & 0.37 & 0.59 & 0.53 & 0.44 & 0.75 & \\
\hline \multirow[t]{2}{*}{$\mathrm{Cl} 2$} & Mean & 4.69 & 4.00 & 4.60 & 3.94 & 4.13 & 4.06 & 4.22 & 4.19 & 35 \\
\hline & $\mathrm{SD}$ & 0.40 & 0.27 & 0.39 & 0.35 & 0.35 & 0.38 & 0.34 & 0.34 & \\
\hline \multirow[t]{2}{*}{$\mathrm{Cl} 3$} & Mean & 4.04 & 4.62 & 4.20 & 5.00 & 4.42 & 4.14 & 4.29 & 4.33 & 65 \\
\hline & $\mathrm{SD}$ & 0.46 & 0.34 & 0.44 & 0.37 & 0.44 & 0.38 & 0.34 & 0.32 & \\
\hline \multirow[t]{2}{*}{$\mathrm{Cl} 4$} & Mean & 3.43 & 3.98 & 3.61 & 4.34 & 3.76 & 3.64 & 3.60 & 3.69 & 40 \\
\hline & $\mathrm{SD}$ & 0.37 & 0.38 & 0.42 & 0.39 & 0.39 & 0.4 & 0.37 & 0.29 & \\
\hline \multirow[t]{2}{*}{ Total } & Mean & 4.16 & 4.09 & 4.19 & 4.30 & 4.04 & 3.92 & 4.06 & 4.11 & 165 \\
\hline & $\mathrm{SD}$ & 0.68 & 0.64 & 0.58 & 0.81 & 0.57 & 0.47 & 0.46 & & \\
\hline
\end{tabular}


Fig. 3 Average cluster ratings of the tested items retrieved after cluster prediction. The overall average rating is 4.11

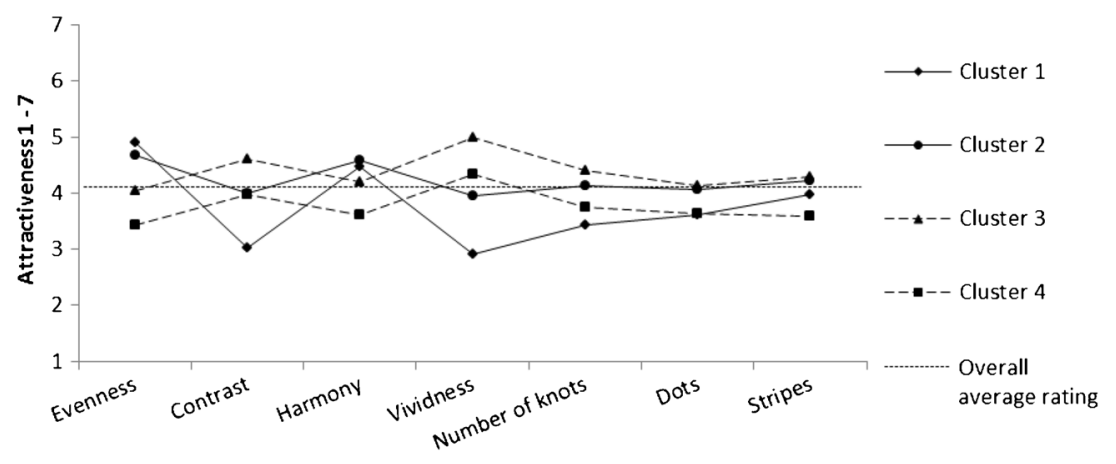

indicates separated clusters but, on the other hand, it also reveals a rather low appreciation for $\mathrm{Cl} 4$, which also obtains the lowest average rating (3.69).

When discussing the results and positive outcomes of the study, some limitations must be considered. The decision to conduct an online survey limited the time to complete the questionnaire, which made it impossible to present all 165 floor samples, not even samples from all $15 \mathrm{VCs}$ to each respondent. It cannot be excluded that the pre-grouping of all floor samples into five pre-groups, out of which five samples were randomly selected, could have affected the results because not all respondents were assessing the same floor samples. As reported by Manuel et al. (2015), a high differentiation into different VCs, can be substantially reduced based on consumers' similarity assessments. Pre-grouping, however, might be avoidable in future studies.

It can be argued that the socio-economic profile of the respondents did not entirely represent 'normal' consumers. They showed a two-peak age distribution, female respondents were under-represented (with $41.9 \%$ ) and the proportion of respondents with a special affinity to wood was higher than that of the average population. To achieve statistically representative results for typical and relevant consumer groups, the enquiry should be substantially extended by both number and profile of the respondents. As the sample in this study is examined in an explorative analysis, it is assumed that without cross-validation, the model's performance is overestimated. From our practical experience we recommend a substantially increased sample size of 500 to 1000 respondents to enable cross-validation. With regard to the socio-demographic effects that may cause differently expressed appreciation, it would be appropriate to examine such effects in more specific studies, even if an earlier study showed no significant effect of some socio-demographic attributes (Manuel et al. 2015).

Furthermore, the results are only valid for Norway spruce floor surfaces, a species which shows a relatively even overall optical wood structure with knots as a major attribute of variation. Exposed to other wood species with more pronounced surface characteristics (e.g., colour, grain pattern) consumers may use different verbal expressions as items to describe and discriminate preferred wood surfaces. Optical colour measurements of the surface were not included, because only boards of one species, Norway spruce with a very uniform natural colour, were tested. Future work might consider the comparison of differently coloured species while examining appreciation and preferences among consumers. Ramananantoandro et al. (2013) measured colour (CIEL*a*b*), texture and density and revealed preferences for darker and yellowish wood surfaces among Antananarivo consumers in the case of a range of 12 species with yellow to red, light to dark, textured and non-textured surfaces used for furniture.

Translating perception into subjective items constitutes one step towards revealing and satisfying consumers' preferred product design and appearance. At this stage (1) floors with clear surfaces and so a minimum of visual surface features (C11) got high appreciation with 'evenness' and 'harmony' and (2) floors with flat grain and pronounced knot features (C13) provoked highest appreciation in this study. Relatively intermediate ratings were given for surfaces with small and visually decent knot features $(\mathrm{Cl} 2)$. Only pith as a unique feature is found separated into $\mathrm{Cl} 4$ and with a relative low appreciation. However, a conversion of quantitatively measurable technical surface parameters into 'appearance classes' based on cluster analysis for the same material is presented in Breinig et al. (2015).

But there remains another knowledge gap to be closed: Producers cut, grade and classify single boards, whereas consumers reveal their preferences (and buy) floors which are composed out of many boards. Consequently, the way boards are put together (composed) to floor surfaces will have an influence on the visual appearance and consumers' judgments. This is especially true, if boards with a 'vivid' appearance with pronounced visual features are composed to floors. In this study, the floor composition from boards of the same visual class (VC) was accomplished by flooring experts taking into account practical experience and reported consumer preferences about a 'balanced' overall appearance (Broman 2001). However, the visual surface characteristics of the entire floor resulting from a specific composition of the single boards were not systematically assessed and quantitatively measured, as e.g. Breinig et al. (2015) did when classifying 
single board surfaces. Thus an appropriate methodological approach to study the influence of alternative floor compositions should be developed and included in further study designs. For decorative parquet flooring, Teischinger (2006) discussed the possibility of letting consumers find out their preferred individual floor composition in the floor showroom on the screen 'playing' with digital images of real parquet elements.

Furthermore, the preferences of consumers regarding floor design may change with time, even if not as quickly as it can be observed with design trends in furniture. Consequently it may be necessary to repeat the inquiries periodically to update the knowledge about actual consumers' preferences.

Finally it must be observed that the presented findings are only valid for German consumers because not only the preferences but also the verbal description may depend on language and cultural background.

\section{Conclusion}

In the case of valuable wood products, the visual appearance is decisive for the consumers' appreciation and preferences. If consumers decide for a preferred wood surface, it may not be clear which visual features cause their specific preferences. In this study, we assume that subjective, verbal items should be identified and 'linked' to surface parameters to close a gap between the verbally stated preference and the product design and production process. If producers care about what surface appearances are appreciated by the consumers, they may achieve advantages in marketing, product design and production. In this study, a set of meaningful items are identified and tested which may be useful for both manufacturers and consumers to communicate product features on the same level of comprehension.

Respondents classified a great variety of wooden floor surfaces with visually pronounced features into four meaningful clusters. Surfaces of distinct or even opposite surface characteristics like surfaces from 'very few' to 'small black knots' versus rather many and especially 'big sound knots' respectively achieve both high overall assessments. Opposite rating is revealed with regard to the items 'harmony' and 'evenness' versus 'contrast' and 'vividness'. The respective wood surface characteristics correspond to 'clear surfaces', 'black knots', 'large sound knots' and 'pith'.

Based on the advanced knowledge and information about consumers' appreciation, advantages for both wood industry and consumers are obvious: Manufacturers can adapt product development, design and marketing according to consumergroup specific demand, with added value not only for conventional premium quality but also for wood surfaces with specific features, formerly regarded as 'defects'. Consumers can select, characterize and buy products which meet their individual preferences more precisely increasing their satisfaction and their willingness-to-pay. Breinig et al. (2013) present an advanced sawmilling concept, how the visual appearance of board surfaces can be quantitatively described and predicted before sawing using 3-D CT Log scanning technology combined with sawing simulation software. Based on the information about actual consumers preferences (Manuel et al. 2015), the raw material selection and the sawing pattern can be directed towards a maximum output of those boards with the most preferred surfaces. This contributes to minimize rejects and to increase the overall added value of the productionto-product-to-marketing chain which begins with the sawing operation already at the log level.

Acknowledgments We would like to thank the sawmill company Echtle in Nordrach, Germany, and the people there who helped to process our material from the logs to floor boards and gave us access to all production lines including digital scanning data. We would also like to extend our thanks to our technical staff Erwin Hummel and Uwe Uhlich at the Chair of Forest Utilization as well as to the team of Lorenz Breinig, Franka Brüchert and Udo H. Sauter at FVA Baden-Württemberg in the Division of Forest Utilization for their tremendous support. Special thanks also to Daniel Hefflebower for proofreading the manuscript in the English language.

\section{Compliance with ethical standards}

Funding This study is part of the research project 'What makes wood so attractive? Transforming people's emotions into material characteristics' which is supported by contract research 'Internationale Spitzenforschung II' of the Baden-Württemberg Stiftung.

\section{References}

Breinig L, Berglund A, Grönlund A, Brüchert F, Sauter UH (2013) Effect of knot detection errors when using a computed tomography log scanner for sawing control. For Prod J 63:263-274. doi:10.13073/ FPJ-D-13-00068

Breinig L, Leonhart R, Broman O, Manuel A, Brüchert F, Becker G (2015) Classification of wood surfaces according to visual appearance by multivariate analysis of wood feature data. J Wood Sci 61: 89-112. doi:10.1007/s10086-014-1410-6

Broman O (1995) Visual impression of features in Scots pine wood surfaces: a qualitative study. For Prod J 45:61-66

Broman O (2001) Aesthetic properties in knotty wood surfaces and their connection with people's preferences. J Wood Sci 47:192-198. doi: 10.1007/BF01171221

Broman O (2003) The measurement of wood features in knotty Scots pine wood surfaces and the connection with people's preferences. In: Developments in image processing and scanning of wood: Selected and edited papers from the 4th International Conference on Image Processing and Scanning of Wood, Mountain Lake, Virginia, USA, 21-23 August, 2000. 8 p. http://pure.ltu.se/portal/ en/publications/the-measurement-of-wood-features-in-knotty-scotspine-wood-surfaces-and-the-connection-with-peoplespreferences(231ec910-96b5-11dd-aadc-000ea68e967b).html, accessed $4^{\text {th }}$ Jan 2016. 
Bumgardner MS, Bush RJ, West CD (2001) Knots as an incongruent product feature: a demonstration of the potential for charactermarked hardwood furniture. J Inst Wood Sci 15:327-336

Bumgardner M, Nicholls D, Barber V (2009) Character-marked furniture made from red alder harvested in southeast Alaska: product perspectives from consumers and retailers. Can J For Res 39:2450-2459. doi:10.1139/X09-154

Hair JF, Black WC, Babin BJ, Anderson RE (2010) Multivariate data analysis. A global perspective, 7th edn. Pearson Education, Upper Saddle River

Høibø O, Nyrud AQ (2010) Consumer perception of wood surfaces the relationship between stated preferences and visual homogeneity. J Wood Sci 56:276-283. doi:10.1007/s10086-009-1104-7

IBM Corp. Released (2013) IBM SPSS statistics for Windows, version 22.0. IBM Corp, Armonk

Krosnick J (1991) Response strategies for coping with the cognitive demands of attitude measures in surveys. Appl Cogn Psychol 5:213236. doi:10.1002/acp. 2350050305

Manuel A, Leonhart R, Broman O, Becker G (2015) Consumers' perceptions and preference profiles for wood surfaces tested with pairwise comparison in Germany. Ann For Sci 72:741-751. doi:10.1007/ s13595-014-0452-7

Nordvik E, Broman NO (2009) Looking at computer-visualized interior wood: a qualitative assessment using focus groups. J Wood Sci 55: 113-120. doi:10.1007/s10086-008-1008-y

Nordvik E, Schütte S, Broman NO (2009) People's perceptions of the visual appearance of wood flooring: a Kansei engineering approach. For Prod J 59:67-74. doi:10.13073/0015-7473-59.11.67

Nyrud AQ (2012) Market-based: focus on customer preferences. International Holzbau-Forum Nordic (IHN 12). http://www. treteknisk.com/fullstory.aspx?m=1578\&amid=17185. Accessed 11 Sep 2015

Nyrud AQ, Roos A, Rødbotten M (2008) Product attributes affecting consumer preference for residential deck materials. Can J For Res 38:1385-1396. doi:10.1139/X07-188

Pakarinen T (1999) Success factors of wood as a furniture material. For Prod J 49:79-85

Ramananantoandro T, Ramanakoto MF, Rajemison AH, Eyma F (2013) Relationship between density and aesthetic attributes of wood and preference of Malagasy consumers. Ann For Sci 70:649-658. doi: 10.1007/s13595-013-0299-3
Rasband WS (2014) ImageJ. U.S. National Institutes of Health, Bethesda, Maryland, USA, http://imagej.nih.gov/ij/, 1997-2014.

Rice J, Kozak R, Meitner M, Cohen D (2006) Appearance wood products and psychological well-being. Wood Fiber Sci 38:644-659

Sande JB, Nyrud AQ (2008) Consumer preferences for wood surfaces - a latent variable approach. In: Proceedings of the biennial meeting of the Scandinavian Society of Forest Economics, Lom, Norway, 6th8th April 2008, Even Bergseng, Grethe Delbeck, Hans Fredrik Hoen (Eds.), 10 p. http://www.treteknisk.no/SSFE 2008 AQN2 j504g. pdf.file, accessed $7^{\text {th }}$ Jan 2016.

Teischinger A (2006) Individual production and design of industrially manufactured multilayer-parquet. In: Berichte aus Energie- und Umweltforschung (BMVIT), Wien, in German, $74 \mathrm{p}$, Bundesministerium für Verkehr, Innovation und Technologie (Pub), Teischinger A (Ed), in German, 74 p. http://www. fabrikderzukunft.at/nw_pdf/8506 holzmanufaktur.pdf, accessed $17^{\text {th }}$ Dec 2015

Tukey JW (1977) Exploratory data analysis, reading. Addison-Wesley, MA

UNIPARK 2014. EFS Survey, (C) 2014 - QuestBack AG. http://www. unipark.com/

Wang QB, Shi GM, Chan-Halbrendt C (2004) Market potential for fine furniture manufactured from low-grade hardwood: evidence from a conjoint analysis in the northeastern United States. For Prod J 54: $19-25$

Weinfurter S, Hansen EN (1999) Softwood lumber quality requirements: examining the supplier/buyer perception gap. Wood Fiber Sci 31: 83-94

Wiedenbeck J, Wiemann M, Alderman D, Baumgras J, Luppold W (2004) Defining hardwood veneer log quality attributes. USDA For. Serv. (Pub.), Newtown Square, Penn. Gen. Tech., Rep. NE313. 40 p. http://www.fs.fed.us/ne/newtown_square/publications/ technical_reports/pdfs/2004/ne gtr313.pdf, accessed $4^{\text {th }}$ Jan 2016

Wiemann $\mathrm{MC}^{-}$(2010) Characteristics and availability of commercially important woods. In: Bergman R, Cai Z, Carll CG, Clausen CA, Dietenberger MA, Falk RH, Frihart CR, Glass SV, Hunt CG, Ibach RE, Kretschmann ER, Rammer ED, Douglas R, Ross RJ (Ed), Wood Handbook, Wood as an engineering material. General Technical Report FPL-GTR-190. USDA For Serv (Pub), Forest Products Laboratory, Madison WI. pp 2.1-2.45. http://www.fpl.fs. fed.us/documnts/fplgtr/fplgtr190/chapter_02.pdf, accessed $4^{\text {th }}$ Jan 2016 